\title{
PERBANDINGAN METODE FUZZY MAMDANI, SUGENO DAN METODE AHP UNTUK PREDIKSI PEMBERIAN PEMILIHAN STOCKIST KLINIK THERAPY BANYU URIP
}

\author{
Arifiyanto Hadinegoro ${ }^{1)}$ \\ 1) Informatika Universitas AMIKOM Yogyakarta \\ email : arifiyanto@amikom.ac.id ${ }^{1)}$,
}

\begin{abstract}
Abstraksi
Stokis merupakan seseorang yang melakukan penjualan dan penawaran barang tertentu, setiap perusahaan pasti memiliki stockist nya masing, dimana setiap stockist bertugas untuk melakukan penawaran dan penjualan terhadap klien yang bersangkutan, beberapa perusahaan selalu memberikan penghargaan terhadap karyawan nya, salah satu nya stockist, parameter nya memiliki beberapa bobot tertentu sehingga perlu metode yang tepat untuk memberikan reward terhadap karyawan, saat ini penggunaan system bisa dijadikan alat untuk mengambil keputusan, beberapa metode yang biasa digunakan adalah AHP dan fuzzy, metode ini memiliki kekurangan dan kelebihan masing masing sehingga cukup menarik jika dua metode ini digunakan pada kasus yang sama, Membandingkan AHP dengan salah satu metode Fuzzy mamdani diharapkan untuk menampilkan perbandingan yang dalam bentuk angka apakah memiliki konsistensi yang sama dan tidak, penelitian ini bukan untuk mencari metode terbaik namun mencari metode paling sesuai terhadap kasus yang dihadapi.
\end{abstract}

\section{Kata Kunci :}

AHP , Fuzzy ,stockist

\begin{abstract}
A stockist is someone who sells and offers certain goods, every company must have its own stockist, where each stockist is tasked with making offers and sales to the client concerned, some companies always give awards to their employees, one of them is a stockist, the parameters have certain weights so that the right method is needed to reward employees, currently the use of the system can be used as a tool to make decisions, some of the methods commonly used are AHP and fuzzy, these methods have their respective advantages and disadvantages so it is quite interesting if these two methods used in the same case, Comparing AHP with one of the Fuzzy Mamdani methods is expected to display a comparison in the form of numbers whether it has the same consistency or not, this study is not to find the best method but to find the most suitable method for a limited number of cases. ap case faced.
\end{abstract}

Keywords :

AHP , Fuzzy, stockist

\section{Pendahuluan}

Karyawan yang menjadi stockist merupakan salah satu andalan dari perusahaan karena sangat mempengaruhi pendapatan dari perusahaan tersebut, Kegiatan stockist yang langsung berinteraksi ke konsumen membutuhkan kemampuan ekstra secara pribadi, dari sini perusahaan harus memberikan motivasi terhadap karyawan stockist salah satu nya dengan memberi reward terhadap karyawan tersebut, namun dari banyak nya karyawan perusahaan tetap membutuhkan parameter karyawan mana yang tepat untuk diberikan reward penghargaan.

Kegiatan menentukan stockist terbaik bisa dibantu dengan penggunaan sebuah sistem yang saat ini dikenal sebagai sistem pendukung keputusan, salah satunya adalah metode AHP ( Analytic Hierarchy Process ) dan juga bisa menggunakan metode fuzzy. Dalam penelitian ini akan membandingkan metode AHP dengan metode Fuzzy Mamdani dalam memberikan rekomendasi stockist terbaik, data data yang digunakan merupakan data dari penelitian sebelumnya yang hanya menggunakan metode AHP di perusahaan Klinik Therapy Banyu Urip dalam laporan skripsi Nissa tahun 2020 [1]. Dilihat dari penelitian sebelumnya teknik pendukung keputusan terdapat yang memiliki metode sederhana seperti Fuzzy yang juga bias digunakan sebagai metode untuk memutuskan sesuatu, dalam penelitian ini peneliti ingin melihat perbandingan antara AHP dengan metode Fuzzy yang lebih sederhana jika diterapkan pada kasus yang sama.

Dalam penelitian ini penulis menggunakan data studi kasus pada penelitian sebelumnya yang hanya menggunakan metode AHP saja, dalam penelitiannya menggunakan 4 parameter sebagai acuan memberikan rekomendasi dan setiap parameter diberikan bobot diantaranya , Penjualan sebesar $56 \%$ penguasaan produk sebesar $25 \%$ 
inovatif sebesar $12 \%$ dan komunikasi sebesar $6 \%$ [1]

AHP juga digunakan oleh sanyoto dan kawan kawan pada tahun 2017 dimana menggunakan metode AHP sebagai sistem pendukung keputusan untuk pemilihan laptop, dimana kresteria cukup banyak hingga cukup mempengaruhi kinerja aplikasi nya [2].

Dalam hal perbandingan juga pernah dilakukan oleh widyasari dan yuwono pada tahun 2018 dimana metode yang digunakan adalah AHP dan fuzzy mamdani dengan studi kasus pemilihan rumah di cepu, dalam penelitian tersebut menggunakan tools matlab sebagai alat untuk menjalankan system nya, dengan hasil perbandingan 1: 0.90298. hasil yang menunjukkan AHP lebih akurat dalam mendukung keputusan pemilihan rumah di CEPU [3].

\section{Metode Penelitian}

Penelitian ini terbagi dalam beberapa tahan pan 1. Studi pustaka, dimana proses ini adalah mencari data referensi dari beberapa hasil penelitian sebelumnya,

2. Observasi, beberapa data yang digunakan di dapat dari data yang langsung di ambil di mitra

3. Eksperimen, dari data yang di dapat di lakukan uji coba simulasi kasus pada tiap perhitungan hingga di dapatkan hasil yang di inginkan.

Tahapan penelitian ini terlihat pada gambar $1 \mathrm{di}$ bawah :

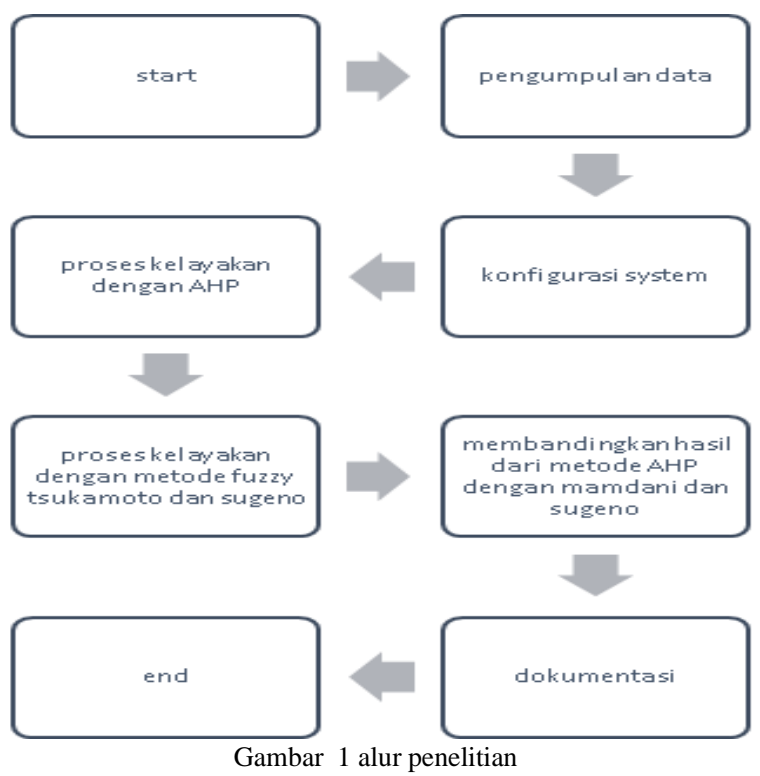

2.1 Analytical Hierarchy Process (AHP) Sebuah hirarki fungsional dengan input utamanya persepsi manusia. Metode ini dikembangkan oleh Prof. Thomas Lorie Saaty dari Wharton Business School di awal tahun 1970, Merupakan metode yang banyak digunakan untuk menentukan beberapa keputusan yang memiliki sifat sebagai berikut :

1. Beberapa kriteria yang sulit untuk di buat kualitatif,

2. Memiliki banyak sub kriteria

3. Banyaknya pengambil keputusan,

4. Kandidat yang terbatas. [4]

\subsection{Metode Mamdani}

Metode ini biasanya dikenal sebagai metode Minmax Untuk memperoleh output, diperlukan 4 tahapan [4].

a. Pembentukan himpunan fuzzy

Pada metode mamdani, baik variable input maupun variabel output dibagi menjadi satu atau lebih himpunan fuzzy.

b. Aplikasi fungsi implikasi

Pada metode mamdani, fungsi implikasi yang digunakan adalah min.

c. Komposisi aturan

Tidak seperti penalaran monoton, apabila sistem terdiri dari beberapa aturan maka inferensi diperoleh dari kumpulan dan korelasi antar aturan. Ada 3 metode yang digunakan dalam melakukan inferensi sistem fuzzy, yaitu : max, additive, probabilistic OR (ptobot).

d. Penegasan (defuzzy).

Beberapa metode fuzzy pada komposisi aturan metode Mamdani.

a. Metode Centroid

Pada metode ini, solusi crips diperoleh dengan cara mengambil titik pusat $\left(\mathrm{z}^{*}\right)$ daerah

fuzzy. Secara umum dirumuskan :

$$
z=\frac{\sum_{j=1}^{T} z j \mu(z j)}{\left.\sum_{j=1}^{T} \mu(z)\right)} z=\frac{\sum_{j=1}^{T} z j \mu(z j)}{\sum_{j=1}^{T} \mu(z j)}
$$

b. Metode Bisektor

c. Metode Min of Maximum (MOM)

d. Metode Smallest of Maximum (SOM)

e. Metode Largest of Maximum (LOM)

\subsection{Metode Fuzzy Sugeno}

pertama kali di ajukan oleh Takagi, Sugeno, dan Kang tahun 1985 dalam upaya untuk membangun pendekatan sistematis untuk membangkitkan aturan - aturan fuzzy dari himpunan data Input - Output. fuzzy ini memiliki penalaran yang sedikit berbeda dari fuzzy mamdani di mana fuzzy sugeno menghasilkan konstanta melainkan berupa konstanta atau persamaan linier [5].

\subsection{Data Penelitian}


Data penelitian yang digunakan dalam penelitian ini merupakan data yang telah ditentukan oleh mitra Stockist Klinik terapi banyu Urip

Dalam proses AHP pihak Klinik Banyuurip mengklasifikasikan solusi yang digunakan seperti terlihat pada tabel 2 di bawah.

Tabel 1 Tabel kriteria

\begin{tabular}{|c|c|c|}
\hline Kriteria & Skala Penilaian & Penjabaran \\
\hline \multirow{4}{*}{$\begin{array}{c}\text { Jumlah } \\
\text { Penjualan }\end{array}$} & (1) Kurang & $<120$ \\
\hline & (2) Cukup & $121-130$ \\
\hline & (3) Baik & $131-140$ \\
\hline & (4) Sangat Baik & $>140$ \\
\hline \multirow{4}{*}{$\begin{array}{c}\text { Penguasaan } \\
\text { Produk }\end{array}$} & (1) Kurang & Kurang menguasai produk \\
\hline & (2) Cukup & Cukup menguasai produk \\
\hline & (3) Baik & Menguasai produk \\
\hline & (4) Sangat Baik & Sangat menguasai produk \\
\hline \multirow[t]{4}{*}{ Inovatif } & (1) Kurang & Kurang inovatif \\
\hline & (2) Cukup & Cukup inovatif \\
\hline & (3) Baik & Inovatif \\
\hline & (4) Sangat Baik & Sangat Inovatif \\
\hline \multirow[t]{4}{*}{ Komunikasi } & (1) Kurang & $\begin{array}{l}\text { Kurang pandai } \\
\text { berkomunikasi }\end{array}$ \\
\hline & (2) Cukup & $\begin{array}{l}\text { Cukup pandai } \\
\text { berkomunikasi }\end{array}$ \\
\hline & (3) Baik & Pandai berkomunikasi \\
\hline & (4) Sangat Baik & $\begin{array}{l}\text { Sangat pandai } \\
\text { berkomunikasi }\end{array}$ \\
\hline
\end{tabular}

Dalam pengujian nanti juga akan digunakan data alternative sebagai data pengujian terhadap aplikasi yang telah dibuat data tersebut terdapat pada table 2 dibawah

Tabel 2 data Stockist

Nama Jumlah Penguasaa Inovatif Komunik

Penjuala n Produk asi

ID

n

\begin{tabular}{llcll}
\hline S001 & Sukma & $\begin{array}{r}\text { 127Sangat } \\
\text { Menguasai }\end{array}$ & Inovatif & Pandai \\
\hline S002 & Basuki & 189Menguasai & Inovatif & Pandai \\
\hline S003 & Joko & $\begin{array}{r}\text { 119Cukup } \\
\text { Menguasai }\end{array}$ & $\begin{array}{l}\text { Cukup } \\
\text { Inovatif }\end{array}$ & $\begin{array}{l}\text { Sangat } \\
\text { Pandai }\end{array}$ \\
\hline S004 & Lina Wati & 134Menguasai & $\begin{array}{l}\text { Sangat } \\
\text { Inovatif }\end{array}$ & Pandai \\
& & 111Sangat & Inovatif & Pandai \\
S005 & Edi & Menguasai & & \\
& Pranoto & & & \\
\hline
\end{tabular}

\subsection{Konfigurasi system}

perancangan struktur hirarki pada metode AHP dan perancangan pada fuzzy . perancangan hirarki perancangan pada AHP di tunjukkan pada gambar dibawah

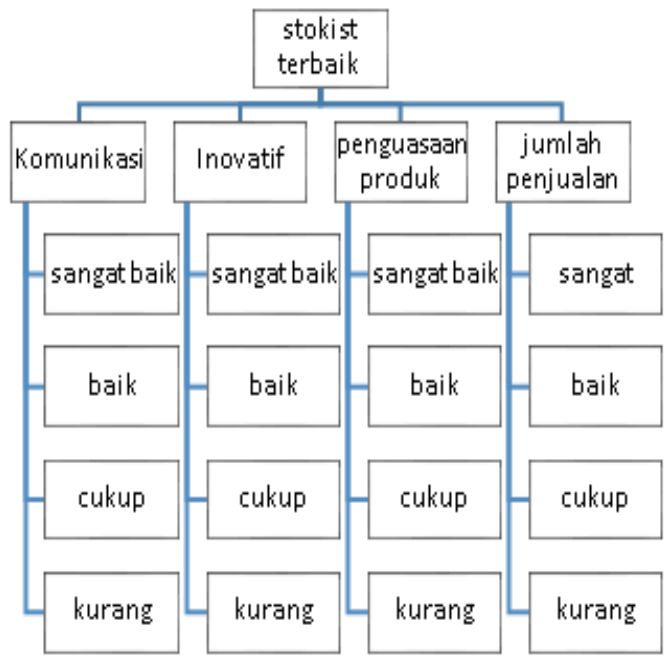

Gambar 2 Kriteria

Dalam AHP pertama yang dilakukan adalah menghitung matrik perbandingan kriteria tabel 3, kemudian menentukan prioritas atau bobot nya ada pada table 4 dan kemudian menghitung konsistensi pada data di table 5

\begin{tabular}{lllll}
\multicolumn{5}{c}{ Tabel 3 Matrik perbandingan kriteria } \\
\hline Kriteria & JP & PP & I & K \\
\hline JP & 1 & 3 & 5 & 5 \\
\hline PP & 0,33 & 1 & 3 & 3 \\
\hline $\mathbf{I}$ & 0,20 & 0,33 & 1 & 2 \\
\hline $\mathbf{K}$ & 0,20 & 0,33 & 0,50 & 1 \\
\hline Jumlah & 1,73 & 4,67 & 9,50 & 11 \\
\hline
\end{tabular}

\begin{tabular}{lllllll}
\hline \multicolumn{7}{c}{ Tabel 4 Kriteria bobot } \\
\hline Kriteria & JP & PP & I & K & Jumlah & Bobot \\
\hline $\mathbf{P P}$ & 0,58 & 0,64 & 0,53 & 0,45 & 2,20 & 0,55 \\
\hline $\mathbf{I}$ & 0,19 & 0,21 & 0,32 & 0,27 & 1,00 & 0,25 \\
\hline $\mathbf{K}$ & 0,12 & 0,07 & 0,11 & 0,18 & 0,47 & 0,12 \\
\hline
\end{tabular}

Tabel 5 Uji konsistensi

\begin{tabular}{lllc}
\hline Kriteria & Bobot & Jumlah & Hasil \\
\hline JP & 0,55 & 1,73 & 0,95 \\
\hline $\mathbf{P P}$ & 0,25 & 4,67 & 1,16 \\
\hline $\mathbf{I}$ & 0,12 & 9,50 & 1,13 \\
\hline $\mathbf{K}$ & 0,08 & & 110,91 \\
\hline & Lamda $(\boldsymbol{\lambda})$ maks & & 4,15 \\
\hline
\end{tabular}

Keterangan :

$\mathrm{JP}=$ Jumlah Penjualan

$\mathrm{PP}=$ Penguasaan Produk

$\mathrm{I}=$ Inovatif 


\section{$\mathrm{K}=$ Komunikasi}

Pada Fuzzy mamdani dan sugeno menggunakan perancangan pada tools yang telah ada

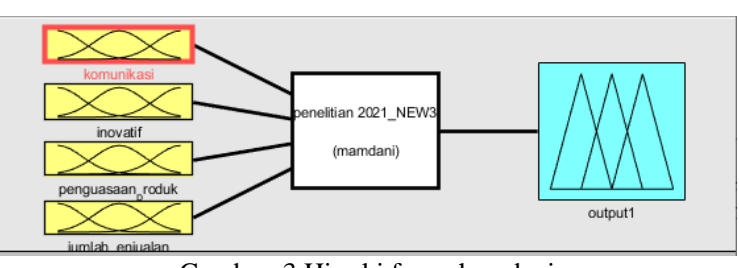

Gambar 3 Hirarki fuzzy hamdani

Fungsi keanggotaan setiap kriteria terdapat pada table 6 dan hasil visual pada tool matlab terlihat pada gambar :

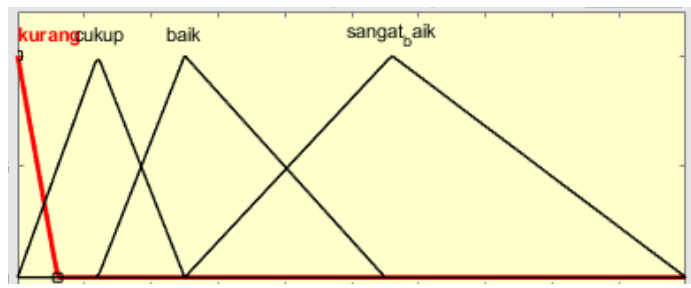

Gambar 4 Membership variabel komunikasi

Tabel 6 Membership fuzzy

\begin{tabular}{|c|c|c|c|}
\hline Kriteria & Skala Penilaian & parameter & bobot \\
\hline \multirow{4}{*}{$\begin{array}{l}\text { Jumlah } \\
\text { Penjualan }\end{array}$} & (1) Kurang & {$\left[\begin{array}{lll}-0.4 & 0 & 0.06\end{array}\right]$} & 0.08 \\
\hline & (2) Cukup & {$\left[\begin{array}{lll}0 & 0.12 & 0.25\end{array}\right]$} & 0.12 \\
\hline & (3) Baik & {$\left[\begin{array}{llll}0.12 & 0.25 & 0.55\end{array}\right]$} & 0.25 \\
\hline & (4) Sangat Baik & {$\left[\begin{array}{llll}0.25 & 0.56 & 1\end{array}\right]$} & 0.55 \\
\hline \multirow{4}{*}{$\begin{array}{c}\text { Penguasaan } \\
\text { Produk }\end{array}$} & (1) Kurang & {$\left[\begin{array}{lll}-0.4 & 0 & 0.06\end{array}\right]$} & 0.08 \\
\hline & (2) Cukup & {$\left[\begin{array}{lll}0 & 0.12 & 0.25\end{array}\right]$} & 0.12 \\
\hline & (3) Baik & {$\left[\begin{array}{llll}0.12 & 0.25 & 0.55\end{array}\right]$} & 0.25 \\
\hline & (4) Sangat Baik & {$\left[\begin{array}{llll}0.25 & 0.56 & 1\end{array}\right]$} & 0.55 \\
\hline \multirow[t]{4}{*}{ Inovatif } & (1) Kurang & {$\left[\begin{array}{llll}-0.4 & 0 & 0.06\end{array}\right]$} & 0.08 \\
\hline & (2) Cukup & {$\left[\begin{array}{llll}0 & 0.12 & 0.25\end{array}\right]$} & 0.12 \\
\hline & (3) Baik & {$\left[\begin{array}{lll}0.12 & 0.25 & 0.55\end{array}\right]$} & 0.25 \\
\hline & (4) Sangat Baik & {$\left[\begin{array}{llll}0.25 & 0.56 & 1\end{array}\right]$} & 0.55 \\
\hline \multirow[t]{4}{*}{ Komunikasi } & (1) Kurang & {$\left[\begin{array}{lll}-0.4 & 0 & 0.06\end{array}\right]$} & 0.08 \\
\hline & (2) Cukup & {$\left[\begin{array}{llll}0 & 0.12 & 0.25\end{array}\right]$} & 0.12 \\
\hline & (3) Baik & {$\left[\begin{array}{lll}0.12 & 0.25 & 0.55\end{array}\right]$} & 0.25 \\
\hline & (4) Sangat Baik & {$\left[\begin{array}{llll}0.25 & 0.56 & 1\end{array}\right]$} & 0.55 \\
\hline
\end{tabular}

Dari tabel membership pada tabel 6 diperoleh 250 rule yang digunakan dalam metode fuzzy mamdani dan sugeno, tampilan dari rule yang di gunakan bisa di lihat pada gambar di bawah

Tabel 7 Tabel Rule metode fuzzy

\section{No RULE \\ 251 If (komunikasi is sangat_kumunikasi) and (Inovatif is sangat_inovatif) and (Penguasaan_produk is sangat_menguasai) and (jmlh_penjualan is kurang) then (output1 is kurang) (1)}

\begin{tabular}{ll}
\hline$\ldots$ & .. \\
\hline $\mathbf{2 5 2}$ & $\begin{array}{l}\text { If (komunikasi is sangat_kumunikasi) and (Inovatif is } \\
\text { sangat_inovatif) and (Penguasaan_produk is } \\
\text { sangat_menguasai) and (jmlh_penjualan is cukup) then } \\
\text { (output1 is baik) (1) }\end{array}$ \\
\hline $\mathbf{2 5 3}$ & $\begin{array}{l}\text { If (komunikasi is sangat_kumunikasi) and (Inovatif is } \\
\text { sangat_inovatif) and (Penguasaan_produk is } \\
\text { sangat_menguasai) and (jmlh_penjualan is sangat_baik) then } \\
\text { (output1 is sangat_baik) (1) }\end{array}$
\end{tabular}

\section{Pembahasan}

Hasil dari perhitungan AHP dan fuzzy dengan data alternative pada tabel 2 di atas adalah sebagai berikut yang ditampilkan dalam bentuk tabel di tabel 8

Tabel 8 Hasil rangking AHP [1]

\begin{tabular}{llll}
\hline RANK & ID & STOCKIST & TOTAL NILAI \\
\hline $\mathbf{1}$ & S002 & Basuki & 0,43 \\
\hline $\mathbf{2}$ & S004 & Lina Wati & 0,30 \\
\hline $\mathbf{3}$ & S001 & Sukma & 0,26 \\
\hline $\mathbf{4}$ & S005 & Edi Pranoto & 0,23 \\
\hline $\mathbf{5}$ & S003 & Joko Mursito & 0,12
\end{tabular}

Dan hasil dari perhitungan Fuzzy madman dan sugeno terlihat pada Tabel 9 dan Tabel 10 di bawah

Tabel 9 Hasil dari fuzzy mamdani

\begin{tabular}{cccc}
\hline Ranking & ID & Stocklist & nilai \\
\hline $\mathbf{1}$ & S002 & Basuki & 0.596 \\
\hline $\mathbf{2}$ & S004 & Lina Wati & 0.298 \\
\hline $\mathbf{3}$ & S001 & Sukma & 0.275 \\
\hline $\mathbf{4}$ & S005 & Edi Pranoto & 0.124 \\
\hline $\mathbf{4}$ & S003 & Joko Mursito & 0.124 \\
\hline \multicolumn{5}{r}{} & Tabel 10 Hasil fuzzy sugeno & \\
\hline $\mathbf{R a n k i n g}$ & ID & Nama & nilai \\
\hline $\mathbf{1}$ & S002 & Basuki & 0.55 \\
\hline $\mathbf{2}$ & S003 & Joko Mursito & 0.25 \\
\hline $\mathbf{2}$ & S001 & Sukma & 0.25 \\
\hline $\mathbf{5}$ & S004 & Edi Pranoto & 0.25 \\
\hline & & Lina Wati & 0.12 \\
\hline
\end{tabular}

Dari data gambar 5 grafik bisa terlihat bahwa AHP memang memiliki konsistensi yang baik karena setiap kriteria dihitung berdasarkan bobot nya dari perbandingan 


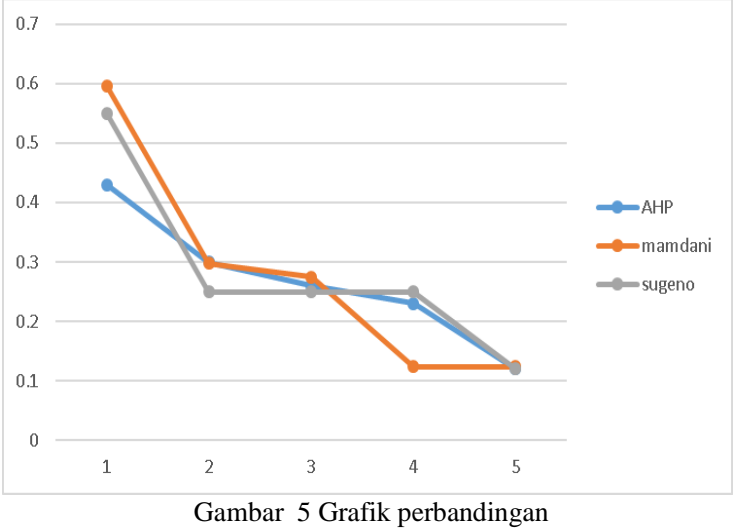

Pada data tertentu nilai fuzzy memiliki nilai sama antar kasus dan ini tidak terjadi pada metode AHP di mana setiap nilai memiliki nilai berbeda beda.

Jika AHP menjadi patokan dan metode Fuzzy menjadi nilai forecast maka didapat nilai MSE untuk metode Fuzzy mamdani 0.007807 dan sugeno 0.00348 jika diTarik kesimpulan data dari metode mamdani lebih baik dibandingkan dengan data dari sugeno, namun lebih baik dari AHP sebagai data real nya,

\section{Kesimpulan}

Berdasarkan hasil , penelitian semua metode yang di cobakan memberikan rekomendasi yang sama untuk peringkat pertamanya namun tidak lebih baik jika terdapat banyak kandidat pada metode fuzzy karena terdapat nilai total yang sama pada satu kondisi , disebabkan Karena metode fuzzy tidak memiliki bobot pada setiap kriteria dan berdasarkan dari konvensional setiap rule saja. Metode AHP akan lebih jika digunakan sebagai pendukung keputusan yang memiliki lebih dari satu kandidat dibandingkan dengan metode fuzzy .

\section{Daftar Pustaka}

[1] N. K. Budiyati, "SISTEM PENDUKUNG KEPUTUSAN PEMILIHAN STOCKIST TERBAIK DENGAN METODE AHP PADA KLINIK THERAPY BANYU URIP," Universitas Amikom Yogyakarta, Yogyakarta, 2020.

[2] G. P. Sanyoto, R. I. Handayani and E. Widanengsih, "SISTEM PENDUKUNG KEPUTUSAN PEMILIHAN LAPTOP UNTUK KEBUTUHAN OPERASIONAL DENGAN METODE AHP (STUDI KASUS: DIREKTORAT PEMBINAAN KURSUS DAN PELATIHAN KEMDIKBUD)," Pilar Nusa Mandiri, vol. 13, no. 2, p. 167, 2017.

[3] A. P. Widyassari and T. Yuwono, "Perbandingan Analytical Hierarchy Process dan Fuzzy Mamdani untuk Sistem Pendukung Keputusan Pemilihan Rumah di Daerah Cepu," Journal of Computer, information system, \& technology management, vol. 1, no. 2, pp. 50-54, 2018.

[4] k

$$
\text { Konsep dan aplikasi }
$$
sistempendukungkeputusan, Yogyakarta: Andi, 2007.

[5] S. N. Marsono, "Penerapan Metode Tsukamoto dalam pemberian kredit sepeda motor bekas pada PT Trijaya motor," santikom, vol. 16, 2017.

[6] F. N. Arieni, D. Halimah and I. Audita, "Implementasi Metode Fuzzy Sugeno Pada Penentuan Harga Emas 24 Karat pada Kota Medan," Jurnal Penerapan Kecerdasan Buatan, vol. 1, no. 2, pp. 116-120, 2020.

[7] S. Kusumadewi, Artificial Intelegent, yogyakarta : Graha Ilmu, 2003. 